\title{
Review \\ Mesenchymal stem cells in arthritic diseases
}

\section{Faye H Chen and Rocky S Tuan}

\begin{abstract}
Cartilage Biology and Orthopaedics Branch, National Institute of Arthritis, and Musculoskeletal and Skin Diseases, National Institutes of Health, Department of Health and Human Services, Building 50, 50 South Dr., Bethesda, MD 20892, USA
\end{abstract}

Corresponding author: Rocky S Tuan, tuanr@mail.nih.gov

Published: 10 October 2008

This article is online at http://arthritis-research.com/content/10/5/223

(c) 2008 BioMed Central Ltd

Arthritis Research \& Therapy 2008, 10:223 (doi:10.1186/ar2514)

\begin{abstract}
Mesenchymal stem cells (MSCs), the nonhematopoietic progenitor cells found in various adult tissues, are characterized by their ease of isolation and their rapid growth in vitro while maintaining their differentiation potential, allowing for extensive culture expansion to obtain large quantities suitable for therapeutic use. These properties make MSCs an ideal candidate cell type as building blocks for tissue engineering efforts to regenerate replacement tissues and repair damaged structures as encountered in various arthritic conditions. Osteoarthritis (OA) is the most common arthritic condition and, like rheumatoid arthritis (RA), presents an inflammatory environment with immunological involvement and this has been an enduring obstacle that can potentially limit the use of cartilage tissue engineering. Recent advances in our understanding of the functions of MSCs have shown that MSCs also possess potent immunosuppression and anti-inflammation effects. In addition, through secretion of various soluble factors, MSCs can influence the local tissue environment and exert protective effects with an end result of effectively stimulating regeneration in situ. This function of MSCs can be exploited for their therapeutic application in degenerative joint diseases such as RA and OA. This review surveys the advances made in the past decade which have led to our current understanding of stem cell biology as relevant to diseases of the joint. The potential involvement of MSCs in the pathophysiology of degenerative joint diseases will also be discussed. Specifically, we will explore the potential of MSC-based cell therapy of OA and RA by means of functional replacement of damaged cartilage via tissue engineering as well as their antiinflammatory and immunosuppressive activities.
\end{abstract}

\section{Introduction}

Mesenchymal stem cells (MSCs), also known in the literature as bone marrow stem cells, skeletal stem cells, and multipotent mesenchymal stromal cells, are nonhematopoietic progenitor cells isolated from adult tissues, and are characterized in vitro by their extensive proliferative ability in an uncommitted state while retaining the potential to differentiate along various lineages of mesenchymal origin, including chondrocyte, osteoblast, and adipocyte lineages, in response to appropriate stimuli (Figure 1). Since the first study by Friedenstein and colleagues [1] more than 40 years ago, the field of MSC investigation has gained increasing attention and popularity, particularly in the past decade. Using 'mesenchymal stem cell' as a key word in a PubMed search, we retrieved 271 papers from 1998, 1,714 in 2007, and 1,185 in 2008 as of 19 July 2008. Initial studies focused on MSC characterization, tissue origin, and the basic biology of MSC growth and differentiation regulation. These studies led to the realization that MSCs can be easily isolated from various tissue sources, readily expanded in culture, and appropriately differentiated under suitable stimulation. These characteristics make MSCs an ideal candidate cell type for tissue engineering efforts aiming to regenerate replacement tissues for diseased structures. Further studies discovered that the regenerative effects of MSCs do not merely rely on their ability to structurally contribute to tissue repair. MSCs possess potent immunomodulatory and anti-inflammatory effects, and through either direct cell-cell interaction or secretion of various factors, MSCs can exert a tremendous effect on local tissue repair through modulating local environment and activation of endogenous progenitor cells. These features make MSC-based cell therapy a hotly pursued subject of investigation in regenerative medicine.

\section{Biology of mesenchymal stem cells Characteristics and tissue distribution}

Originally derived from bone marrow [1,2], MSCs and MSClike cells have been identified to exist in and can be isolated from a large number of adult tissues, where they are postulated to carry out the function of replacing and regenerating local cells that are lost to normal tissue turnover, injury, or aging. These tissues include adipose, periosteum, synovial membrane, synovial fluid (SF), muscle, dermis, deciduous

3-D = three-dimensional; BMP = bone morphogenetic protein; CIA = collagen-induced arthritis; ECM = extracellular matrix; FLS = fibroblast-like synoviocyte; GVHD = graft-versus-host disease; IFN- $\gamma=$ interferon-gamma; IL = interleukin; $\mathrm{MHC}=$ major histocompatibility complex; $\mathrm{MMP}=$ matrix metalloproteinase; MSC = mesenchymal stem cell; NF- $\mathrm{KB}=$ nuclear factor-kappa-B; NK = natural killer; OA = osteoarthritis; PBMC = peripheral blood mononuclear cell; PTHrP = parathyroid hormone-related protein; RA = rheumatoid arthritis; SF = synovial fluid; TGF- $\beta=$ transforming growth factor-beta; TNF- $\alpha=$ tumor necrosis factor-alpha; Treg $=$ regulatory $\mathrm{T}$ cell. 
Figure 1

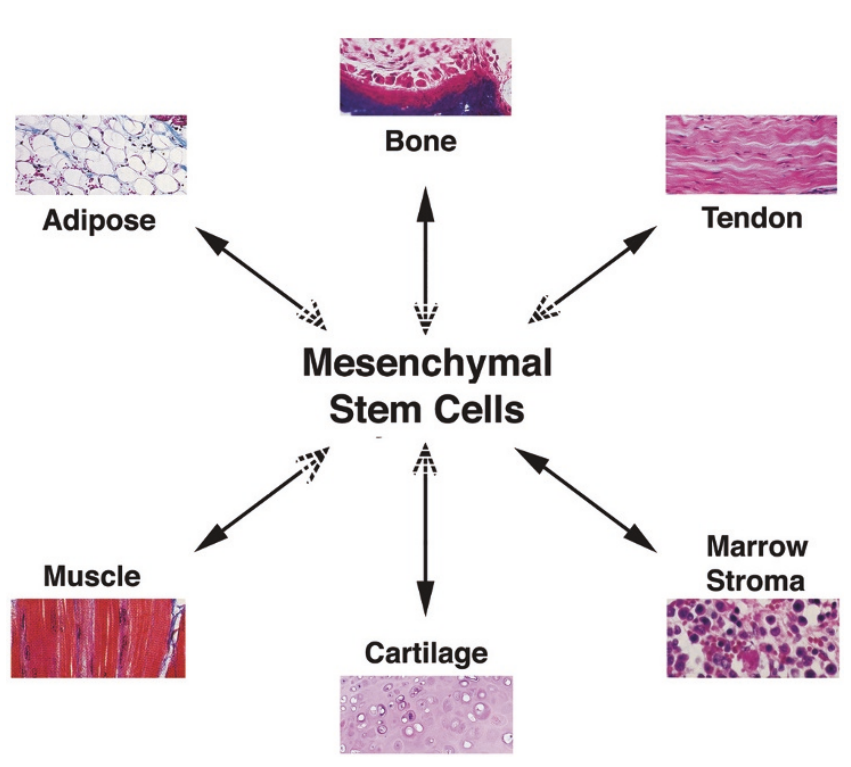

Multilineage differentiation potential of mesenchymal stem cells (MSCs). Under appropriate conditions, MSCs are able to differentiate into cell types of different lineages, including bone, cartilage, adipose, muscle, tendon, and stroma. The arrows are presented as bidirectional, indicating that differentiated MSCs are capable of dedifferentiation and transdifferentiation. Adapted from [89].

teeth, pericytes, trabecular bone, infrapatellar fat pad, and articular cartilage (reviewed in [3-5]). Despite the intense research on MSCs, however, there is no uniformly accepted clear and specific definitive phenotype or surface markers for the prospective isolation of MSCs. Instead, MSCs are defined retrospectively by a constellation of characteristics in vitro, including a combination of phenotypic markers and multipotential differentiation functional properties. The minimal requirement for a population of cells to qualify as MSCs, as suggested by the International Society for Cytotherapy, is threefold: (a) they must be plastic adherent under standard culture conditions, (b) they should express CD105, CD73, and CD90 and lack the expression of CD45, CD34, CD14 or CD11b, CD79 $\alpha$ or CD19, and HLA-DR surface molecules, and (c) they should possess tripotential mesodermal differentiation capability into osteoblasts, chondrocytes, and adipocytes [6]. While this minimal set of standard criteria was meant to foster a more uniform characterization of MSCs and facilitate the exchange of data among investigators, it will probably require modification as evolving research gives rise to new knowledge. Although plastic adherence serves as the most commonly used and simple isolation procedure, various positive and negative surface markers (for example, Stro-1, CD146/melanoma cell adhesion molecule, CD271/low-affinity nerve growth factor, and stagespecific embryonic antigen-4 [7]) have also been used to enrich MSC yield and homogeneity. Recently, Buhring and colleagues [8] described a panel of surface markers, including
CD140b (platelet-derived growth factor receptor-D), CD340 (HER-2/erbB2), and CD349 (frizzled-9) in conjunction with CD217, that can be used for MSC enrichment. However, the enriched cell fractions are still heterogeneous, and the majority of isolated cells are not clonogenic.

Although MSCs isolated from different tissues show similar phenotypic characteristics, it is not clear whether these are the same MSCs, and they clearly show different propensities in proliferation and differentiation potentials in response to stimulation with various growth factors. A study that compared human MSCs derived from bone marrow, periosteum, synovium, skeletal muscle, and adipose tissue revealed that synovium-derived MSCs exhibited the highest capacity for chondrogenesis, followed by bone marrowderived and periosteum-derived MSCs [9]. Isolation methods, culture surface, medium, and seeding density as well as treatment with various growth factors influence the expansion and differentiation and immunogenic properties of MSCs [10]. Donor age and disease stage can also influence MSC yield, proliferation rate, and differentiation potential. Of particular relevance to rheumatic diseases, some studies have shown that age, rheumatoid arthritis (RA), and advanced osteoarthritis (OA) disease stage adversely affect MSCs derived from the bone marrow of patients, with significantly reduced proliferative capacity and chondrogenic activity compared with those from young healthy donors, although these findings are debated [11-13]. In one study, bone marrow-derived MSCs from RA and OA patients showed chondrogenic potential similar to that of MSCs isolated from healthy donors [14]. In another study, compared with MSCs from healthy donors, MSCs from individuals with RA showed similar frequency, differentiation potential, survival, and immunophenotypic characteristics, but RA patient MSCs showed impaired clonogenic and proliferative potential with premature telomere length loss [13]. However, irrespective of age or OA disease etiology, it has been found that a sufficient number of MSCs with adequate chondrogenic differentiation potential can be isolated. Therefore, a therapeutic application of MSCs for cartilage regeneration of RA and OA lesions seems feasible.

\section{Mesenchymal stem cell differentiation potential and control}

MSCs are characterized by their intrinsic self-renewal capacity which is reflected in its clonogenic property and multilineage differentiation potential. Under defined conditions, MSCs can differentiate into chondrocytes, osteoblasts, and adipocytes, and they also serve as hematopoiesis-supporting stromal cells $[2,15]$ (Figure 1). MSCs have also been reported, albeit controversially, to differentiate into myocytes and cardiomyocytes and even into cells of nonmesodermal origin, including hepatocytes and neurons [16].

MSC chondrogenesis is a complex process and an active area of research. Much of our understanding of the relevant 
molecules and processes stems from our knowledge of healthy cartilage homeostasis as well as cartilage formation in the developing limb [17]. The standard experimental model consists of a three-dimensional (3-D) culture of MSCs, as high-density cell pellet or micromass culture or in a 3-D scaffold, under the stimulation of suitable chondrogenic factors. Elements including activations of various intracellular signaling pathways (mitogen-activated protein kinases and Smads) and transcription factors (sox9, L-sox5, and L-sox6), production and interaction with extracellular matrix (ECM) proteins (collagen type II, aggrecan, and cartilage oligomeric matrix protein), activities of soluble bioactive factors such as growth factors, cytokines, chemokines, and hormones, and effects of environmental factors such as mechanical loading and oxygen tension all affect chondrogenic differentiation of MSCs (Figure 2). One of the most important molecules intrinsic to the assumption of the cartilaginous phenotype is the transcription factor sox9. In bone marrow-derived MSCs, expression of exogenous sox 9 led to increased proteoglycan deposition [18].

Growth factors that have regulatory effects on MSCs include members of the transforming growth factor-beta (TGF- $\beta$ ) superfamily, the insulin-like growth factors, the fibroblast growth factors, the platelet-derived growth factor, and Wnts. Among these growth factors, TGF- $\beta$ s, including TGF- $\beta 1$, TGF- $\beta 2$, and TGF- $\beta 3$, as well as bone morphogenetic proteins (BMPs) are the most potent inducers to promote chondrogenesis of MSCs. For human MSCs, TGF- $\beta 2$ and TGF- $\beta 3$ were shown to be more active than TGF- $\beta 1$ in promoting chondrogenesis in that, although cellular content is similar after culture, significantly more proteoglycans and collagen type II can be produced [19]. BMPs, known for their involvement in cartilage formation, act alone or in concert with other growth factors to induce or enhance MSC chondrogenic differentiation. For example, BMP-2, BMP-4, or BMP-6, combined with TGF- $\beta 3$, induced chondrogenic phenotype in cultured human bone marrow-derived MSC pellets, with BMP-2 seemingly the most effective [20]. For adipose tissue-derived MSCs, due to their lack of expression of TGF- $\beta$ type I receptor and reduced expression of BMP-2, BMP-4, and BMP-6 when compared with bone marrow MSCs, supplementation with BMP- 6 and TGF- $\beta$ seems to be optimal for their chondrogenic differentiation, with BMP-6 stimulating stronger chondrogenic differentiation compared with TGF- $\beta$ [21]. Wnt signaling pathway protein polymorphism and altered gene expression have recently been associated with RA and OA [22,23]. Canonical Wnt signaling in coordination with TGF- $\beta$ and BMP signaling has been shown to enhance MSC differentiation [24,25]. In addition, canonical and noncanonical Wnts have been shown to cross-talk with each other in regulating stem cell proliferation and osteogenic differentiation [26].

While MSCs can be induced to undergo chondrogenic differentiation, with current systems and knowledge, the end result is often less than desirable, with inferior cartilagerelated properties coupled with problematic terminal differentiation. In one study, bovine MSCs were compared directly with articular chondrocytes from the same animals for their cartilage-forming capacity [27]. Both cell types were cast into an agarose hydrogel system and cultured under the same chondrogenic conditions with the stimulation of TGF- $\beta$. While MSCs underwent chondrogenic differentiation as indicated by cartilage ECM expression, the amount and mechanical properties of the ECM were inferior to those produced by the chondrocytes. These results suggest that further optimization is needed for the successful use of MSCs for cartilage tissue engineering. The other challenge in controlling MSC chondrogenesis is the premature hypertropic terminal differentiation of MSCs undergoing chondrogenic differentiation. Hypertropic maturation of MSCs is characterized by the premature expression of collagen type $\mathrm{X}$, matrix metalloproteinase-13 (MMP-13), and alkaline phosphatase activity that is normally found in growth plate cartilage but not in stable healthy articular cartilage. The expression of collagen type $\mathrm{X}$ can be detected early during MSC chondrogenesis, and it is debatable whether its expression does signal true hypertrophic differentiation [28]; however, it has been correlated with the unstable transient nature of transplanted tissue in vivo, which leads to vascular invasion and calcification [29]. Various factors are involved in the regulation of hypertropic differentiation. The TGF- $\beta$ family of growth factors and their intracellular signaling molecules are involved in chondrogenesis, including terminal differentiation [30]. TGF- $\beta$ can inhibit chick sternal chondrocyte terminal differentiation, as shown by suppression of expression of collagen type $X$ and alkaline phosphatase [31]. On the other hand, BMP-2 can induce terminal differentiation [32,33], and in chick sternal chondrocytes, this process can be inhibited by the BMP antagonist chordin [33]. It has been shown that the combination of isolation and culture condition as well as the use of different BMPs can influence the outcome and extent of MSC chondrogenesis progression as well as their terminal hypertrophy [34]. Furthermore, similar to growth plate development in which hypertrophic maturation is under the regulation of a feedback loop involving Indian hedgehog and parathyroid hormone-related protein (PTHrP) [35], PTHrP also plays a regulatory role in MSC terminal differentiation. When human bone marrow MSCs from OA patients were cultured in a 3-D polyglycolic acid scaffold in the presence of TGF- $\beta 3$, upregulated expression of collagen type $X$ was significantly suppressed by the presence of PTHrP whereas expression of other cartilage-specific matrix proteins was not affected [36].

Taken together, these findings suggest a complex interplay of extracellular growth factor molecules, signal transduction pathways, and transcription factor networks for the control of MSC chondrogenesis. Optimization of chondrogenesis to generate stable cartilage suitable for clinical use is likely cell source-dependent and will likely be a function of cellular 


\section{MSC for cartilage tissue engineering and regeneration}

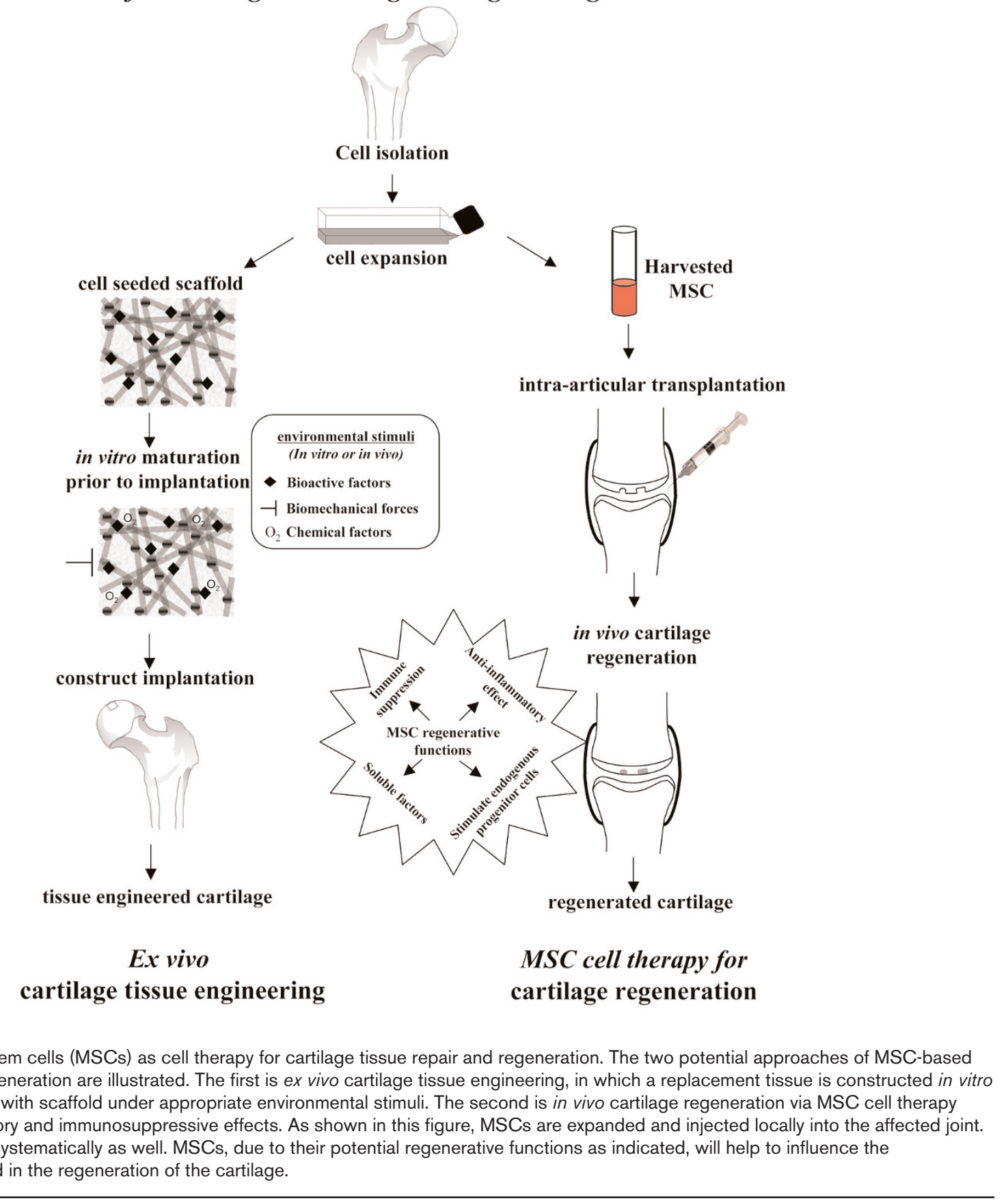

context, microenvironment as well as properties, dose, and timing of the molecules administered to the cells [4,37].

\section{Immunoregulatory properties of mesenchymal stem cells}

A very important property of MSCs, especially for their use in rheumatic diseases, is their potent immunosuppressive and anti-inflammatory functions that have been demonstrated both in vitro and in vivo. Due to the scarcity of MSCs, especially the apparent decrease in quantity and quality with age and diseases, as well as the fact that patient-derived MSCs have the same genetic defects as the patient, it is sometimes desirable to consider using allogeneic MSCs for therapy. Traditionally, allogeneic cell treatment has required accompanying immunosuppression therapy. However, in the case of MSCs, this may not always be necessary as it has 
been shown that MSCs can be used to modulate host immune systems and confer immune suppression function. However, caution should be exercised as this field of research is still maturing and conflicting results have been obtained in different systems from different labs.

First, MSCs are hypoimmunogenic and can evade the host immune elimination. MSCs express low (fetal) to intermediate (adult) major histocompatibility complex (MHC) class I molecules and do not express MHC class II molecules on their cell surface, although an intracellular pool of $\mathrm{MHC}$ class II molecules can be stimulated to be expressed on the cell surface by interferon-gamma (IFN- $\gamma$ ) [38]. However, since MSCs do not express any costimulatory molecules, including B7-1 (CD80), B7-2 (CD86), or CD40, they do not activate alloreative $\mathrm{T}$ cells [39]. After differentiation into adipocytes, osteoblasts, and chondrocytes, MSCs continue to express $\mathrm{MHC}$ class I but not class II molecules on their cell surface, even under stimulation, and continue to be nonimmunogenic [38]. These properties suggest that MSCs should be able to be transplanted to an allogeneic host without immune rejection and that in vivo MSC cell therapy and tissueengineered cartilage construct using allogeneic MSCs transplanted in vivo in hypoimmunogenic biomaterial scaffolds should not elicit a host immune response. However, the immune privilege of MSCs seems to be limited. A few studies in mouse systems have reported that, in vivo, allogeneic mismatched MSCs were rejected by the host and could not form ectopic bone, while syngeneic recipient allowed ectopic bone formation, despite the fact that, in vitro, the MSCs showed immunosuppressive activity $[40,41]$.

MSCs not only evade detection and elimination by the immune system but can further modulate and suppress alloreactivity through modulating most major immune cell activities [38,39,42-53]. In vitro, MSCs inhibit T-cell proliferation and activation in response to mitogenic or antigenic stimulation in a dose-dependent manner. Numerous studies [38,39,42-48] have shown that MSCs, as well as their differentiated progenies of adipocytes, osteoblasts, or chondrocytes, inhibit proliferation of allogeneic lymphocytes. Both naïve and memory T cells as well as $\mathrm{CD}^{+}$and $\mathrm{CD}^{+}$ T cells in mixed lymphocyte cultures were suppressed. Furthermore, MSCs suppress $\mathrm{CD}^{+} \mathrm{T}$ cell-mediated lysis. $T$ cells were found to be anergic and arrest in the $G_{0}-G_{1}$ phase of the cell cycle.

In addition to $\mathrm{T}$ cells, MSCs exert proliferation inhibitory effects on B cells [49], natural killer (NK) cells [50,51], and dendritic cells $[44,45,52,53]$. In addition to the effect on proliferation, MSCs can further interfere and affect cellular differentiation and maturation and function of the immune cells $[44,45,52,53]$. MSCs inhibit the maturation and decrease the expression of presentation molecules and costimulatory molecules of antigen-presenting cells [53]. MSCs can also inhibit B-cell antibody production [49]. In the case of NK cells, MSCs can suppress their proliferation, cytokine secretion, and cytotoxicity [45,50,51]. Furthermore, MSCs not only have a direct inhibitory effect on $\mathrm{T}$ cells but also affect the first critical step of immune response in that they can inhibit the differentiation and maturation of the antigen-presenting cells and cause the dendritic cells to switch cytokine secretion profile to decrease their secretion of proinflammatory cytokines such as tumor necrosis factoralpha (TNF- $\alpha$ ), IFN- $\gamma$, and interleukin-12 (IL-12) and, importantly, increase production of IL-10 which is suppressive and tolerogenic and a potent inducer of regulatory $T$ cells (Tregs) $[44,45,53]$. In addition, it has been reported [45] that human MSCs caused an increase in the proportion of Tregs present. Overall, the effect of MSCs on the immune cells is to skew the immune response toward a tolerant and anti-inflammatory phenotype. These immunomodulative effects seem not to be limited to MSCs but are shared by other mesenchymal cells. Progenies of MSC differentiation as well as various stromal cells from different tissues, including chondrocytes and fibroblasts, have also been shown to have immunosuppressive effects under certain conditions $[38,46]$.

The mechanism of the immunomodulatory effects of MSCs is not completely understood, although both direct and indirect effects have been suggested through either cell-cell interaction or soluble factors that create a local immunosuppressive environment. MSCs alter the cytokine secretion profile of dendritic cells, naïve and effector T cells, and NK cells to induce a more anti-inflammatory or tolerant phenotype. Secretion of the proinflammatory cytokines, TNF- $\alpha$ and IFN- $\gamma$, is decreased whereas that of the more suppressive IL4 and IL-10 is stimulated [45]. Other factors involved have been shown to include hepatocyte growth factor, TGF- $\beta 1$, IL10, IL-6, prostaglandin $\mathrm{E}_{2}$, nitric oxide, and possibly indoleamine 2,3-dioxygnease. Although the precise mechanism has yet to be clarified (reviewed in $[42,43]$ ), the body of evidence suggests that MSCs are immunosuppressive and anti-inflammatory and can be transplanted between MHCincompatible individuals.

The immunosuppressive effects of MSCs have also been demonstrated in vivo. The first of such studies was carried out in baboons in which systematic administration of allogeneic MSCs was used to prolong skin graft [47]. In an animal model of experimental autoimmune encephalomyelitis that mimics human multiple sclerosis, MSC administration strikingly ameliorated disease. MSCs were effective when administered at disease onset and at the peak of disease but not after disease stabilization. This effect was believed to be mediated through inducing T-cell anergy [48]. The immunosuppressive function of MSCs has also been shown to be effective in humans. In one report, MSCs were used to treat severe steroid-refractory graft-versus-host disease (GVHD), resulting in the disappearance of GVHD in six out of eight patients, with their survival rate being significantly better than that of patients not treated with MSCs [54]. In animal 
models, MSC implantations improved outcomes of renal, lung, and cardiac injuries, at least partially by shifting the microenvironment at the injury sites from proinflammatory to anti-inflammatory [55-57]. In a murine pulmonary fibrosis model, MSCs inhibited bleomycin-induced inflammation and fibrosis within the lungs. This was shown to be due primarily to the secretion of IL-1 receptor antagonist by MSCs [56]. MSC-conditioned medium was shown to block proliferation of an IL- $1 \alpha$-dependent T-cell line and inhibit production of TNF- $\alpha$ by activated macrophages in vitro. Furthermore, MSC administration was more effective than recombinant IL-1 receptor antagonist delivered via either adenoviral infection or osmotic pumps in inhibiting bleomycin-induced increases in TNF- $\alpha$, IL- $1 \alpha$, and trafficking of lymphocytes and neutrophils into the lung [56]. These successful animal studies have led to additional human studies, which include phase I/II clinical trials on GVHD, acute myocardial infarction, end-stage ischemic heart diseases, osteogenesis imperfecta, multiple sclerosis, and open bone fracture (see [58] for review and [59] for a list of ongoing clinical trials).

The studies on the effect of MSCs on immunomodulation, along with other studies, also attest to another critical aspect regarding the function of MSCs, that is, the trophic effects of MSCs. In most in vivo studies except for those using in vitro engineered constructs, significant engraftment of MSCs was not observed whereas the potent beneficial effects of MSCs were obvious. It thus appears that MSCs can secrete soluble factors that can be anti-inflammatory, immunomodulatory, and supportive for tissue repair through activating the regenerative potential of the endogenous progenitor cells. In line with this notion, MSCs have been used in vivo for enhancing the engraftment of other tissues (for example, hematopoietic stem cells). MSCs can support hematopoiesis through the secretion of cytokines and have the capacity to maintain and expand lineage-specific colony-forming units from $\mathrm{CD} 34^{+}$marrow cells in long-term bone marrow culture $[60,61]$, and when cotransplanted, can enhance hematopoietic stem cell engraftment and increase the success of hematopoietic stem cell transplantation in clinical outcomes [62-64]. It is reasonable to anticipate that MSC therapy in conjunction with hematopoietic stem cell transplantation can be used for treating autoimmune diseases, such as RA, to possibly bypass the immunoablasive conditioning step and tissue toxicity as a result of the immunomodulation function of MSCs. This is expected to be an intensely pursued area of research in the next few years.

The immune-suppressive function of MSCs brings caution to its use under certain conditions. One of the concerns relates to the potential interplay between MSCs and tumors. It has been shown that MSCs, especially mouse MSCs, will accumulate cytogenetic aberrations and become neoplastic after a few passages in culture $[65,66]$. Human MSCs seem to be more stable in culture during the standard in vitro culture time of 6 to 8 weeks; however, they can also undergo spontaneous transformation following long-term in vitro culture (4 to 5 months) involving the mesenchymal-epithelial transition process [67]. Therefore, care should be taken when MSCs are expanded for clinical use. This is especially true for the potential allogeneic 'off-the-shelf' approach, whereas autologous MSC treatment should not require such a long expansion time when enough original material is used. There has also been some debate on the effect of in vitro expanded MSCs on tumor growth. MSCs have the capacity to engraft into multiple tissues in vivo, especially to sites of injury and inflammation, including primary tumor and tissue sites of metastasis. The effect of MSCs on tumor growth has been somewhat controversial. There are reports that MSCs promote tumor growth and metastasis as well as studies to the contrary (reviewed in [68]). The contradictory results probably relate to the different tumors and models used and to the differences stemming from the heterogeneity and different culture methods of MSCs. Nevertheless, the ability of MSCs to target tumors has given rise to a potential therapeutic way of cancer therapy to specifically deliver antitumor drugs in situ. MSCs genetically modified to express antitumor factors, including IL-12 and antagonist for hepatic growth factor, have been used. The therapeutic application for MSCs on tumor growth requires further investigation to rule out the potential side effects of MSCs.

\section{Mesenchymal stem cells in rheumatic diseases}

The ease of isolation and expansion and the multipotential differentiation capacity, especially the chondrogenic differentiation property of MSCs, make MSCs the cell type of choice for articular cartilage tissue engineering that aims to replace and regenerate the diseased structure in joint diseases. In addition, their immunomodulatory and anti-inflammatory functions make MSCs the ideal candidate for cell therapy to treat diseases with inflammatory features such as those encountered in OA and RA, although research in this area is just starting to gain momentum. Therefore, MSCs are actively being considered as candidate cells for the treatment of arthritic joint diseases both as a structural substitute and as a stand-alone cell therapy or as a combination thereof (Figure 2). The involvement of MSCs in OA and RA and their potential use for their treatment are discussed below.

\section{Mesenchymal stem cell and osteoarthritis}

$\mathrm{OA}$ is the most common type of arthritis. It is estimated that 26.9 million Americans 25 years old or older have clinical OA of some joints, with a higher percentage of affliction in the older population [69]. Its clinical manifestations include joint pain and impairment to movement, and surrounding tissues are often affected with local inflammation. The etiology of OA is not completely understood; however, injury, age, and genetics have been considered among the risk factors. $\mathrm{OA}$ is a progressively debilitating disease that affects mostly cartilage, with associated changes in bone. Cartilage has limited intrinsic healing and regenerative capacities. Current 
pharmacologic treatment for early $O A$ has seen limited success, and various surgical procedures, including debridement, drilling, osteochondral transplantation, autologous perichondral and periosteal grafts, and autologous chondrocyte implantation, are able to relieve pain temporarily but eventually fail [70]. Due to the increasing incidence of OA and the aging population coupled with inefficient therapeutic choices, novel cartilage repair strategies are in need.

The availability of large quantities of MSCs and their potential for ready chondrogenic differentiation after prolonged in vitro expansion have made MSCs the most hopeful candidate progenitor cell source for cartilage tissue engineering. MSCs loaded on a 3-D scaffold under appropriate differentiation cues can undergo chondrogenic differentiation, and the resulting construct can be used as a replacement tissue for cartilage repair (Figure 2). In vitro cartilage tissue engineering has attracted a lot of research effort and attention from biologists, engineers, and clinicians in the past 10 years. The regulation and control of this process have been extensively reviewed above and elsewhere and readers are referred to these publications for additional information $[4,71,72]$. In addition to being used for structural replacement as the aim of cartilage tissue engineering in cartilage repair, MSCs have been used directly in cell therapy for OA cartilage repair in situ. OA is associated with progressive and often severe inflammation. For tissue engineering or cell therapy to be successful, measures must be taken to control such an inflammatory environment. Because MSCs have been shown to possess anti-inflammatory function, they are also a suitable cell type for this purpose. Several characteristics of MSCs make them attractive in this respect. First, MSCs have been shown to be able to migrate and engraft onto multiple musculoskeletal tissues, especially sites of injury, and undergo site-specific differentiation. More importantly, while there, MSCs can exert significant effects on local environment and resident endogenous tissue progenitor cells through direct or indirect interactions and soluble factors. In addition, MSCs have shown potent anti-inflammatory and immunosuppressive activities. Taken together, these properties make MSCs a promising candidate for cell therapy for diseases that often involve the immune system, such as OA and RA (Figure 2).

A study by Murphy and colleagues [73] employing MSCs in a goat OA model highlighted the regenerative effect of MSC cell therapy in OA. Trauma-induced OA was simulated in this model by unilateral excision of the medial meniscus and resection of the anterior cruciate ligament, followed by exercise. Autologous MSCs in hyaluronan solution were injected intra-articularly to test their effect. In the control animals without MSCs, OA development was observed as expected, with substantial fibrillation and erosion of large areas of articular cartilage, accompanied by osteophyte formation and changes to the subchondral bone. In the MSCtreated joints, there was marked regeneration of the medial meniscus and decreased cartilage destruction and bone changes. Injected labeled MSCs were not observed to be engrafted on articular cartilage. Labeled MSCs were seen engrafted in the neomeniscus, though not in a large enough quantity to account for the majority of the newly formed tissue. These findings suggested that the beneficial effect of MSCs on cartilage protection and on OA progression was not due to the direct structural contribution of MSCs. Based on knowledge gained from other systems, it is possible that the injected MSCs in this case acted to induce endogenous progenitor cells through various direct or indirect interactions to regenerate meniscus, which in turn retarded cartilage degeneration associated with OA. Based on the goat study, a procedure using direct injection of adult stem cells into the patient's knee to repair meniscus and prevent OA progression is currently in a phase I/II clinical trial.

The above study highlights another challenge in using MSCs systematically or locally for arthritis prevention and treatment, that is, the inefficient engraftment of MSCs to the articular cartilage. In one experiment, the engraftment, survival, and long-term fate of human MSCs were assessed after in utero transplantation in sheep, and transplanted cells were shown to persist and undergo site-specific differentiation into chondrocytes, adipocytes, myocytes and cardiomyocytes, bone marrow stromal cells, and thymic stroma. However, although most of the animals had human cell engraftment in various tissues, cartilage-specific engraftment was not efficient [74]. In another study, plastic adherence-enriched bone marrow mesenchymal precursor cells were systematically transplanted via tail vein injection into irradiated mice [75]. After 1 to 5 months, the donor cells were found in bone, cartilage, and lung in addition to marrow and spleen. When chondrocytes were isolated from xiphoid and articular cartilage by microscopic dissection, progeny of the donor cells accounted for $2.5 \%$ of the isolated chondrocytes. Although donor cells were found to engraft onto articular cartilage of irradiated mice, albeit at low efficiency, assays of control nonirradiated mice revealed very low levels of the donor cells at the same time points [75]. In studies with different models of induced arthritis, including a traumainduced goat OA model [73] and a mouse model of collageninduced arthritis (CIA) [76], transplanted cells were not detected in joint cartilage. Investigation into the mechanisms of MSC trafficking and homing, possibly through the regulation of various chemokines and receptors, as well as adhesion molecules and their receptors (reviewed in [77]), is currently an actively pursued area of research and will likely provide insights into means of increasing engraftment of MSCs onto articular cartilage for more efficient treatment of arthritis. Despite the low engraftment efficiency, MSC-based procedures have been found to exert a therapeutic effect in various disease models, including arthritis, possibly through their trophic effect and their anti-inflammatory and immunosuppressive activities, which can significantly affect the local environment and resident endogenous tissue progenitor cells in carrying out the regenerative function. 


\section{Mesenchymal stem cell and rheumatoid arthritis}

RA is a complex multisystem autoimmune disease characterized by cartilage and bone destruction associated with local production of inflammatory mediators, such as TNF- $\alpha$ and IL-1 $\beta$. The etiology of RA is not completely understood, and multiple cells are thought to contribute to the pathogenic progression, with T cells [78] and fibroblast-like synoviocytes (FLSs) [79] playing central roles in orchestrating the disease progression of inflammation and tissue damage. Although it is still debatable, RA is believed to be a T cell-driven inflammatory synovitis disease in which $T$ cells and synoviocytes participate in a complex network of cell- and mediator-driven events leading to joint destruction. Both antigen-activated $\mathrm{CD}^{+} \mathrm{T}$ helper 1 (Th1) and CD8 ${ }^{+} \mathrm{T}$ cells are reported to be involved in the pathogenesis of RA. After being triggered and activated, $T$ cells stimulate monocytes, macrophages, and FLSs to produce inflammatory mediators, including IL-1, TNF- $\alpha$, IFN- $\gamma$, and IL- 6 , and secrete MMPs, leading to the systemic inflammation that eventually results in joint destruction $[78,80]$. Pharmacological interventions aiming at reducing inflammation, including methotrexate and anti-TNF- $\alpha$ drugs (infliximab, adalimumab, and etanercept), have been used to treat RA symptoms [81]. Recently, for patients who do not respond to conventional treatment, autologous hematopoietic stem cell transplantation after immune ablation treatment has become an option. However, this comes with a high risk of side effects, including mortality. Joint destruction in RA and the anti-inflammatory and immune-suppressive properties of MSCs suggest that RA may be a candidate disease for cartilage and bone repair using MSC therapy.

MSCs have been identified in synovium and SF that share characteristics of bone marrow derived-MSCs, with clonogenic and multipotential differentiation potentials. The origin of SF-MSCs is not clear. From gene array profiling, it has been observed that SF-MSCs are more similar to synovial MSCs than bone marrow MSCs [82]. This finding can suggest that SF-MSCs are derived from synovium instead of bone marrow or are the result of phenotypic changes due to their local environment. Furthermore, the relationship between FLS and MSC is not fully elucidated. It has been reported that a fraction of the RA FLS population shows properties that are associated with MSCs in that they can differentiate into chondrocytes, osteoblasts, adipocytes, and muscle cells despite the pathological condition [83-85]. By means of a mouse model of bone marrow transplantation in which bone marrow cells from green fluorescence protein-transgenic donor mice were transplanted into lethally irradiated recipient mice, it was shown that normal FLSs contain a minor fraction $(1.2 \%)$ of bone marrow-derived mesenchymal cells. At the onset of CIA in a mouse model of RA, before inflammation, primitive bone marrow stromal cells migrated from the bone marrow into the affected joint cavity and appeared to contribute to synovial proliferation, and this process is dependent on the proinflammatory cytokine TNF- $\alpha$ [83].
Upon CIA development, the arthritic FLSs contain a substantial portion (33.7\%) of bone marrow-derived cells [84]. These cells can differentiate in vitro into various mesenchymal cell types, but inflammatory cytokines such as IL-1 $\beta$ prevent the multilineage differentiation. The transcription factor nuclear factor-kappa-B (NF-KB), which can be activated by proinflammatory cytokines, plays a key role in the repression of osteogenic and adipogenic differentiation of arthritic FLS. Furthermore, specific activation of NF-KB profoundly enhances FLS proliferation, motility, and secretion of matrix-degrading MMP-13. Therefore, it is proposed that arthritic FLSs are, in fact, MSCs which are arrested at early stages of differentiation by inflammation activation of NF-KB [84]. In another study, MSCs from RA and healthy donors were compared. RA MSCs showed frequency, differentiation potential, survival, and immunophenotypic characteristics similar to those of normal MSCs, but impaired clonogenic and proliferative potential with premature telomere length loss [13].

Currently, the biological roles MSCs play in RA pathophysiology are unknown. However, MSCs isolated from RA patients and patients with other autoimmune diseases seem to be similar to normal MSCs in that they are clonogenic and possess multipotential differentiation capacity. More importantly, they can also inhibit the proliferation of autologous and allogeneic peripheral blood mononuclear cells (PBMCs) in a dose-dependent manner. The inhibition was observed with MSCs and PBMCs either from healthy donors or from patients suffering from autoimmune diseases [86]. This indicates that MSCs from RA patients can potentially be used for immunomodulatory cell therapy. Recently, in a more specific study, allogeneic MSCs were tested against T cells from RA patients which react to collagen type II [87]. MSCs or MSC-differentiated chondrocytes were able to inhibit collagen type II-stimulated T-cell proliferation and activation in a dose-dependent manner. In addition, MSCs and their chondrocyte progeny alike inhibited the secretion of proinflammatory cytokines IFN- $\gamma$ and TNF- $\alpha$ by $\mathrm{CD}^{+}$and $\mathrm{CD}^{+}$cells while increasing the secretion of $\mathrm{IL}-10$ and restoring the secretion of IL- 4 . It was also shown that TGF- $\beta$ played a significant role in the inhibitory effects of MSCs in this case.

So far, the in vivo use of MSCs for treating RA has generated mixed results. CIA is an experimental autoimmune disease that shares several clinical and histological features with RA. $\mathrm{CIA}$ can be elicited in susceptible strains of rodents and nonhuman primates by immunization with collagen type II, the major matrix constituent protein of articular cartilage. In a CIA mouse model, a single injection of MSCs prevented the occurrence of severe irreversible damage to bone and cartilage [76]. Using cell tracking, donor cells were not detected in joints of treated mice, suggesting that the injected MSCs did not restore tissue integrity by mechanisms of direct tissue repair. At the end of the experiment, cells were not evident in peritoneal or secondary lymphoid organs, 
although cells were detected in the intermediate time point. In terms of mechanism, MSC treatment induced hyporesponsiveness of $\mathrm{T}$ lymphocytes from MSC-treated mice in that they showed basal in vitro proliferation and mitogen-induced and collagen type II-recalled proliferation compared with T cells from non-MSC-treated animals. MSC treatment modulated the expression of proinflammatory cytokines. In particular, serum concentration of TNF- $\alpha$ was significantly decreased. It was suggested that MSCs exerted their immunomodulatory function by educating antigen-specific Tregs. In MSC-treated immunized mice, CD4+CD25+CD27+ Tregs were increased significantly compared with non-MSC-treated mice, and Tregs from these mice inhibited proliferation of $T$ lymphocytes when proliferation was recalled using collagen type II. These results suggest an effective therapeutic approach to target the pathogenic mechanism of autoimmune arthritis using allogeneic MSCs.

In another CIA study, mouse stem cell line C3H10T1/2 did not confer any benefit. In vitro experiments showed that the addition of TNF- $\alpha$ was sufficient to reverse the immunosuppressive effect of MSCs on T-cell proliferation [88]. These data suggest that environmental parameters, in particular those related to inflammation, may influence the immunosuppressive properties of MSCs.

\section{Conclusion}

The potential use of MSCs as building blocks for joint tissue replacement via tissue engineering and their newly uncovered potential for direct cell therapy by virtue of their trophic and anti-inflammatory and immunosuppressive properties (Figure 2) have generated a lot of enthusiasm in orthopaedics and rheumatology communities. A large body of research has produced exciting data, leading to the hope of their potential application. However, controversy still exists, and a great deal of work needs to be done before MSCs can be accepted for clinical therapeutic applications.

Research on MSCs and their use in various rheumatic diseases has been clearly gaining attention and momentum. The need for successful therapy in treating these diseases warrants more investment in research and development, both at the fundamental level of basic biology and in more translational studies. Fundamental knowledge of MSC identification, isolation, culture, and differentiation still requires extensive and intensive studies. The lack of an unambiguous definition and isolation of MSCs and the heterogeneity of MSCs alone, resulting in inadequately defined cell populations isolated by different groups, most likely contributed to some of the different and often contradictory results reported so far. For cartilage tissue engineering, the principal challenge is to find the optimal and most effective cues for cartilage formation in vitro, be it growth factors tailored for the specific MSCs, bioactive scaffolds, or the enhancing environmental factors, with the goal of generating a stable replacement articular cartilage

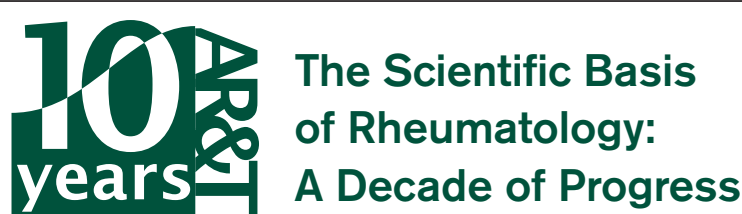

This article is part of a special collection of reviews, The Scientific Basis of Rheumatology: A Decade of Progress, published to mark Arthritis Research \& Therapy's 10th anniversary.

Other articles in this series can be found at: http://arthritis-research.com/sbr

tissue that has appropriate mechanical properties and can integrate with the host tissues with proper stable long-term functions. Research on the in vivo MSC niche and the regulation of this microenvironment will prove to be of pivotal importance to determine how best to use MSCs to modulate the local environment and endogenous progenitor cells for repair and regeneration purposes. It is clear that the evolving and rapidly developing research on the immunomodulatory and anti-inflammatory effects of MSCs will improve our knowledge of the mechanism and regulation of this phenomenon. While caution should be exercised in the clinical application of MSC therapy on arthritic patients, contingent upon the confirmation of additional conclusive animal studies, we believe that MSCs offer great hope in relieving the disease burden of degenerative joint diseases through their application in the form of replacement tissue as well as local or systemic cell therapy.

\section{Competing interests}

The authors declare that they have no competing interests.

\section{Acknowledgements}

This work was supported by the Intramural Research Program of the National Institute of Arthritis and Musculoskeletal and Skin Diseases, National Institutes of Health (Bethesda, MD, USA) (Z01 AR41131).

\section{References}

1. Friedenstein AJ, Piatetzky-Shapiro I, Petrakova KV: Osteogenesis in transplants of bone marrow cells. J Embryol Exp Morphol 1966, 16:381-390.

2. Pittenger MF, Mackay AM, Beck SC, Jaiswal RK, Douglas R, Mosca JD, Moorman MA, Simonetti DW, Craig S, Marshak DR: Multilineage potential of adult human mesenchymal stem cells. Science 1999, 284:143-147.

3. Mimeault M, Batra SK: Recent progress on tissue-resident adult stem cell biology and their therapeutic implications. Stem Cell Rev 2008, 4:27-49.

4. Chen FH, Rousche KT, Tuan RS: Technology insight: adult stem cells in cartilage regeneration and tissue engineering. Nat Clin Pract Rheumatol 2006, 2:373-382.

5. Bianco P, Robey PG, Simmons PJ: Mesenchymal stem cells: revisiting history, concepts, and assays. Cell Stem Cell 2008, 2:313-319.

6. Dominici M, Le Blanc K, Mueller I, Slaper-Cortenbach I, Marini F Krause D, Deans R, Keating A, Prockop D, Horwitz E: Minimal criteria for defining multipotent mesenchymal stromal cells. 
The International Society for Cellular Therapy position statement. Cytotherapy 2006, 8:315-317.

7. Jones $\mathrm{E}, \mathrm{McG}$ onagle $\mathrm{D}$ : Human bone marrow mesenchymal stem cells in vivo. Rheumatology (Oxford) 2008, 47:126-131.

8. Buhring HJ, Battula VL, Treml S, Schewe B, Kanz L, Vogel W: Novel markers for the prospective isolation of human MSC. Ann N Y Acad Sci 2007, 1106:262-271.

9. Sakaguchi Y, Sekiya I, Yagishita K, Muneta T: Comparison of human stem cells derived from various mesenchymal tissues: superiority of synovium as a cell source. Arthritis Rheum 2005, 52:2521-2529.

10. Sotiropoulou PA, Perez SA, Salagianni M, Baxevanis CN, Papamichail M: Characterization of the optimal culture conditions for clinical scale production of human mesenchymal stem cells. Stem Cells 2006, 24:462-471.

11. Murphy JM, Dixon K, Beck S, Fabian D, Feldman A, Barry F: Reduced chondrogenic and adipogenic activity of mesenchymal stem cells from patients with advanced osteoarthritis. Arthritis Rheum 2002, 46:704-713.

12. Sethe $S$, Scutt A, Stolzing A: Aging of mesenchymal stem cells. Ageing Res Rev 2006, 5:91-116.

13. Kastrinaki MC, Sidiropoulos $P$, Roche S, Ringe J, Lehmann S, Kritikos H, Vlahava VM, Delorme B, Eliopoulos GD, Jorgensen C, Charbord P, Häupl T, Boumpas DT, Papadaki HA: Functional, molecular and proteomic characterisation of bone marrow mesenchymal stem cells in rheumatoid arthritis. Ann Rheum Dis 2008, 67:741-749.

14. Dudics V, Kunstar A, Kovacs J, Lakatos T, Geher P, Gomor B, Monostori E, Uher F: Chondrogenic potential of mesenchymal stem cells from patients with rheumatoid arthritis and osteoarthritis: measurements in a microculture system. Cells Tissues Organs 2008, PMID:18562787.

15. Prockop DJ: Marrow stromal cells as stem cells for nonhematopoietic tissues. Science 1997, 276:71-74.

16. Jiang $Y$, Jahagirdar $B N$, Reinhardt RL, Schwartz RE, Keene $C D$, Ortiz-Gonzalez XR, Reyes M, Lenvik T, Lund T, Blackstad M, Du J, Aldrich S, Lisberg A, Low WC, Largaespada DA, Verfaillie CM: Pluripotency of mesenchymal stem cells derived from adult marrow. Nature 2002, 418:41-49.

17. Tuan RS: Biology of developmental and regenerative skeletogenesis. Clin Orthop Relat Res 2004, 427:S105-117.

18. Tsuchiya $H$, Kitoh $H$, Sugiura $F$, Ishiguro $N$ : Chondrogenesis enhanced by overexpression of sox 9 gene in mouse bone marrow-derived mesenchymal stem cells. Biochem Biophys Res Commun 2003, 301:338-343.

19. Barry F, Boynton RE, Liu B, Murphy JM: Chondrogenic differentiation of mesenchymal stem cells from bone marrow: differentiation-dependent gene expression of matrix components. Exp Cell Res 2001, 268:189-200.

20. Sekiya I, Larson BL, Vuoristo JT, Reger RL, Prockop DJ: Comparison of effect of BMP-2, -4 , and -6 on in vitro cartilage formation of human adult stem cells from bone marrow stroma. Cell Tissue Res 2005, 320:269-276.

21. Hennig T, Lorenz H, Thiel A, Goetzke K, Dickhut A, Geiger F, Richter W: Reduced chondrogenic potential of adipose tissue derived stromal cells correlates with an altered TGFbeta receptor and BMP profile and is overcome by BMP-6. J Cell Physiol 2007, 211:682-691.

22. Rousche KT, Basksh D, Tuan RS: Wnt signaling for targeted therapies in rheumatology. In Further Targeted Therapies in Rheumatology. Edited by Smolen JS, Lipsky PE. London, UK: Taylor \& Francis; 2007

23. Sen $M$ : Wnt signalling in rheumatoid arthritis. Rheumatology (Oxford) 2005, 44:708-713.

24. Zhou S, Eid K, Glowacki J: Cooperation between TFG-beta and Wnt pathways during chondrocyte and adipocyte differentiation of human marrow stromal cells. J Bone Miner Res 2004, 19:463-470.

25. Tuli R, Tuli S, Nandi S, Huang X, Manner PA, Hozack WJ, Danielson KG, Hall DJ, Tuan RS: Transforming growth factor-b-mediated chondrogenesis of human mesenchymal progenitor cells involves $\mathrm{N}$-cadherin and mitogen-activated protein kinase and Wnt signaling cross-talk. J Biol Chem 2003, 278: 41227-41236.

26. Baksh D, Tuan RS: Canonical and non-canonical Wnts differentially affect the development potential of primary isolate of human bone marrow mesenchymal stem cells. J Cell Physiol
$2007,212: 817-826$

27. Mauck RL, Yuan X, Tuan RS: Chondrogenic differentiation and functional maturation of bovine mesenchymal stem cells in long-term agarose culture. Osteoarthritis Cartilage 2006, 14: 179-189.

28. Mwale F, Stachura D, Roughley $P$, Antoniou J: Limitations of using aggrecan and type $X$ collagen as markers of chondrogenesis in mesenchymal stem cell differentiation. $J$ Orthop Res 2006, 24:1791-1798.

29. Pelttari K, Winter A, Steck E, Goetzke K, Hennig T, Ochs BG, Aigner T, Richter $\mathrm{W}$ : Premature induction of hypertrophy during in vitro chondrogenesis of human mesenchymal stem cells correlates with calcification and vascular invasion after ectopic transplantation in SCID mice. Arthritis Rheum 2006, 54:3254-3266

30. Mello MA, Tuan RS: Effects of TGF-beta1 and triiodothyronine on cartilage maturation: in vitro analysis using long-term highdensity micromass cultures of chick embryonic limb mesenchymal cells. J Orthop Res 2006, 24:2095-2105

31. Ferguson CM, Schwarz EM, Reynolds PR, Puzas JE, Rosier RN, O'Keefe RJ: Smad2 and 3 mediate transforming growth factorbeta1-induced inhibition of chondrocyte maturation. Endocrinology 2000, 141:4728-4735.

32. Valcourt U, Gouttenoire J, Moustakas A, Herbage D, Mallein-Gerin F: Functions of transforming growth factor-beta family type I receptors and Smad proteins in the hypertrophic maturation and osteoblastic differentiation of chondrocytes. J Biol Chem 2002, 277:33545-33558

33. Zhang D, Ferguson CM, O'Keefe RJ, Puzas JE, Rosier RN, Reynolds PR: A role for the BMP antagonist chordin in endochondral ossification. J Bone Miner Res 2002, 17:293-300.

34. Taipaleenmaki H, Suomi S, Hentunen T, Laitala-Leinonen T, Saamanen AM: Impact of stromal cell composition on BMP. induced chondrogenic differentiation of mouse bone marrow derived mesenchymal cells. Exp Cell Res 2008, 314:24002410.

35. Vortkamp A, Lee K, Lanske B, Segre GV, Kronenberg HM, Tabin $\mathrm{CJ}$ : Regulation of rate of cartilage differentiation by Indian hedgehog and PTH-related protein. Science 1996, 273:613622.

36. Kafienah W, Mistry S, Dickinson SC, Sims TJ, Learmonth I, Hollander AP: Three-dimensional cartilage tissue engineering using adult stem cells from osteoarthritis patients. Arthritis Rheum 2007, 56:177-187.

37. Lozito $\mathrm{T}$, Kolf $\mathrm{C}$, Tuan RS: Microenvironmental regulation of adult mesenchymal stem cells. In Regulatory Networks in Stem Cells. Edited by Rajasekhar VK and Vemuri MC. New York, NY: Humana Press/Springer; 2008.

38. Le Blanc K, Tammik C, Rosendahl K, Zetterberg E, Ringden O: HLA expression and immunologic properties of differentiated and undifferentiated mesenchymal stem cells. Exp Hematol 2003, 31:890-896.

39. Tse WT, Pendleton JD, Beyer WM, Egalka MC, Guinan EC: Suppression of allogeneic T-cell proliferation by human marrow stromal cells: implications in transplantation. Transplantation 2003, 75:389-397.

40. Prigozhina TB, Khitrin S, Elkin G, Eizik O, Morecki S, Slavin S: Mesenchymal stromal cells lose their immunosuppressive potential after allotransplantation. Exp Hematol 2008, PMID:18619727.

41. Eliopoulos N, Stagg J, Lejeune L, Pommey S, Galipeau J: Allogeneic marrow stromal cells are immune rejected by MHC class I- and class II-mismatched recipient mice. Blood 2005, 106:4057-4065.

42. Le Blanc K, Ringden O: Immunomodulation by mesenchymal stem cells and clinical experience. J Intern Med 2007, 262: 509-525.

43. Uccelli A, Pistoia V, Moretta L: Mesenchymal stem cells: a new strategy for immunosuppression? Trends Immunol 2007, 28: 219-226.

44. Beyth S, Borovsky Z, Mevorach D, Liebergall M, Gazit Z, Aslan H, Galun E, Rachmilewitz J: Human mesenchymal stem cells alter antigen-presenting cell maturation and induce T-cell unresponsiveness. Blood 2005, 105:2214-2219.

45. Aggarwal S, Pittenger MF: Human mesenchymal stem cells modulate allogeneic immune cell responses. Blood 2005, $105: 1815-1822$ 
46. Jones S, Horwood N, Cope A, Dazzi F: The antiproliferative effect of mesenchymal stem cells is a fundamental property shared by all stromal cells. J Immunol 2007, 179:2824-2831.

47. Bartholomew A, Sturgeon C, Siatskas M, Ferrer K, Mclntosh K, Patil S, Hardy W, Devine S, Ucker D, Deans R, Moseley A, Hoffman R: Mesenchymal stem cells suppress lymphocyte proliferation in vitro and prolong skin graft survival in vivo. Exp Hematol 2002, 30:42-48.

48. Zappia E, Casazza S, Pedemonte E, Benvenuto F, Bonanni I, Gerdoni E, Giunti D, Ceravolo A, Cazzanti F, Frassoni F, Mancardi G, Uccelli A: Mesenchymal stem cells ameliorate experimental autoimmune encephalomyelitis inducing T-cell anergy. Blood 2005, 106:1755-1761.

49. Corcione A, Benvenuto F, Ferretti E, Giunti D, Cappiello V, Cazzanti F, Risso M, Gualandi F, Mancardi GL, Pistoia V, Uccelli A: Human mesenchymal stem cells modulate B-cell functions. Blood 2006, 107:367-372.

50. Spaggiari GM, Capobianco A, Abdelrazik H, Becchetti F, Mingari MC, Moretta L: Mesenchymal stem cells inhibit natural killercell proliferation, cytotoxicity, and cytokine production: role of indoleamine 2,3-dioxygenase and prostaglandin $\mathrm{E}_{2}$. Blood 2008, 111:1327-1333.

51. Sotiropoulou PA, Perez SA, Gritzapis AD, Baxevanis CN, Papamichail $M$ : Interactions between human mesenchymal stem cells and natural killer cells. Stem Cells 2006, 24:74-85.

52. Ramasamy R, Fazekasova H, Lam EW, Soeiro I, Lombardi G, Dazzi F: Mesenchymal stem cells inhibit dendritic cell differentiation and function by preventing entry into the cell cycle. Transplantation 2007, 83:71-76.

53. Jiang $X X$, Zhang $Y$, Liu $B$, Zhang $S X, W u Y, Y u X D$, Mao $N$ : Human mesenchymal stem cells inhibit differentiation and function of monocyte-derived dendritic cells. Blood 2005, 105: 4120-4126.

54. Ringdén $O$, Uzunel $M$, Rasmusson I, Remberger $M$, Sundberg $B$, Lönnies H, Marschall HU, Dlugosz A, Szakos A, Hassan Z, Omazic B, Aschan J, Barkholt L, Le Blanc K: Mesenchymal stem cells for treatment of therapy-resistant graft-versus-host disease. Transplantation 2006, 81:1390-1397.

55. Togel F, Hu Z, Weiss K, Isaac J, Lange C, Westenfelder C: Administered mesenchymal stem cells protect against ischemic acute renal failure through differentiation-independent mechanisms. Am J Physiol Renal Physiol 2005, 289:F3142.

56. Ortiz LA, Dutreil M, Fattman C, Pandey AC, Torres G, Go K, Phinney DG: Interleukin 1 receptor antagonist mediates the antiinflammatory and antifibrotic effect of mesenchymal stem cells during lung injury. Proc Natl Acad Sci U S A 2007, 104: 11002-11007.

57. Guo J, Lin GS, Bao CY, Hu ZM, Hu MY: Anti-inflammation role for mesenchymal stem cells transplantation in myocardial infarction. Inflammation 2007, 30:97-104.

58. Giordano A, Galderisi U, Marino IR: From the laboratory bench to the patient's bedside: an update on clinical trials with mesenchymal stem cells. J Cell Physiol 2007, 211:27-35.

59. ClinicalTrials.gov homepage [http://clinicaltrials.gov].

60. Majumdar MK, Thiede MA, Haynesworth SE, Bruder SP, Gerson SL: Human marrow-derived mesenchymal stem cells (MSCs) express hematopoietic cytokines and support long-term hematopoiesis when differentiated toward stromal and osteogenic lineages. J Hematother Stem Cell Res 2000, 9:841848.

61. Cheng L, Qasba $P$, Vanguri $P$, Thiede MA: Human mesenchymal stem cells support megakaryocyte and pro-platelet formation from CD34(+) hematopoietic progenitor cells. J Cell Physiol 2000, 184:58-69.

62. Koc ON, Gerson SL, Cooper BW, Dyhouse SM, Haynesworth SE, Caplan Al, Lazarus HM: Rapid hematopoietic recovery after coinfusion of autologous-blood stem cells and cultureexpanded marrow mesenchymal stem cells in advanced breast cancer patients receiving high-dose chemotherapy. $J$ Clin Oncol 2000, 18:307-316.

63. Almeida-Porada G, Porada CD, Tran N, Zanjani ED: Cotransplantation of human stromal cell progenitors into preimmune fetal sheep results in early appearance of human donor cells in circulation and boosts cell levels in bone marrow at later time points after transplantation. Blood 2000, 95:3620-3627.

64. Ringden O, Uzunel M, Sundberg B, Lonnies L, Nava S, Gustafs- son J, Henningsohn L, Le Blanc K: Tissue repair using allogeneic mesenchymal stem cells for hemorrhagic cystitis, pneumomediastinum and perforated colon. Leukemia 2007, 21:2271-2276.

65. Tolar J, Nauta AJ, Osborn MJ, Panoskaltsis Mortari A, McElmurry RT, Bell S, Xia L, Zhou N, Riddle M, Schroeder TM, Westendorf JJ, Mclvor RS, Hogendoorn PC, Szuhai K, Oseth L, Hirsch B, Yant SR, Kay MA, Peister A, Prockop DJ, Fibbe WE, Blazar BR: Sarcoma derived from cultured mesenchymal stem cells. Stem Cells 2007, 25:371-379.

66. Miura M, Miura Y, Padilla-Nash HM, Molinolo AA, Fu B, Patel V, Seo BM, Sonoyama W, Zheng JJ, Baker CC, Chen W, Ried T, Shi $\mathrm{S}$ : Accumulated chromosomal instability in murine bone marrow mesenchymal stem cells leads to malignant transformation. Stem Cells 2006, 24:1095-1103.

67. Rubio D, Garcia S, De la Cueva T, Paz MF, Lloyd AC, Bernad A, Garcia-Castro J: Human mesenchymal stem cell transformation is associated with a mesenchymal-epithelial transition. Exp Cell Res 2008, 314:691-698.

68. Lazennec G, Jorgensen C: Concise review: adult multipotent stromal cells and cancer: risk or benefit? Stem Cells 2008, 26: 1387-1394.

69. Lawrence RC, Felson DT, Helmick CG, Arnold LM, Choi H, Deyo RA, Gabriel S, Hirsch R, Hochberg MC, Hunder GG, Jordan JM, Katz JN, Kremers HM, Wolfe F; National Arthritis Data Workgroup: Estimates of the prevalence of arthritis and other rheumatic conditions in the United States. Part II. Arthritis Rheum 2008, 58:26-35.

70. Hunziker EB: Articular cartilage repair: basic science and clinical progress. A review of the current status and prospects. Osteoarthritis Cartilage 2002, 10:432-463.

71. Chen FH, Tuan RS: Adult stem cells for cartilage tissue engineering and regeneration. Curr Rhematol Rev 2008, 4:149154.

72. Noth $U$, Steinert AF, Tuan RS: Technology insight: adult mesenchymal stem cells for osteoarthritis therapy. Nat Clin Pract Rheumatol 2008, 4:371-380.

73. Murphy JM, Fink DJ, Hunziker EB, Barry FP: Stem cell therapy in a caprine model of osteoarthritis. Arthritis Rheum 2003, 48: 3464-3474.

74. Liechty KW, MacKenzie TC, Shaaban AF, Radu A, Moseley AM, Deans R, Marshak DR, Flake AW: Human mesenchymal stem cells engraft and demonstrate site-specific differentiation after in utero transplantation in sheep. Nat Med 2000, 6:12821286.

75. Pereira RF, Halford KW, O'Hara MD, Leeper DB, Sokolov BP, Pollard MD, Bagasra O, Prockop DJ: Cultured adherent cells from marrow can serve as long-lasting precursor cells for bone, cartilage, and lung in irradiated mice. Proc Natl Acad Sci U S A 1995, 92:4857-4861.

76. Augello A, Tasso R, Negrini SM, Cancedda R, Pennesi G: Cell therapy using allogeneic bone marrow mesenchymal stem cells prevents tissue damage in collagen-induced arthritis. Arthritis Rheum 2007, 56:1175-1186.

77. Fox JM, Chamberlain G, Ashton BA, Middleton J: Recent advances into the understanding of mesenchymal stem cell trafficking. Br J Haematol 2007, 137:491-502.

78. Fournier C: Where do T cells stand in rheumatoid arthritis? Joint Bone Spine 2005, 72:527-532.

79. Mor A, Abramson SB, Pillinger MH: The fibroblast-like synovial cell in rheumatoid arthritis: a key player in inflammation and joint destruction. Clin Immunol 2005, 115:118-128.

80. Fox DA: The role of $T$ cells in the immunopathogenesis of rheumatoid arthritis: new perspectives. Arthritis Rheum 1997, 40:598-609.

81. Toussirot E, Wendling D: The use of TNF-alpha blocking agents in rheumatoid arthritis: an update. Expert Opin Pharmacother 2007, 8:2089-2107.

82. Morito T, Muneta T, Hara K, Ju YJ, Mochizuki T, Makino $\mathrm{H}$, Umezawa A, Sekiya I: Synovial fluid-derived mesenchymal stem cells increase after intra-articular ligament injury in humans. Rheumatology (Oxford) 2008, 47:1137-1143.

83. Marinova-Mutafchieva L, Williams RO, Funa K, Maini RN, Zvaifler $\mathrm{NJ}$ : Inflammation is preceded by tumor necrosis factor-dependent infiltration of mesenchymal cells in experimental arthritis. Arthritis Rheum 2002, 46:507-513.

84. Li X, Makarov SS: An essential role of NF-kappaB in the 
'tumor-like" phenotype of arthritic synoviocytes. Proc Natl Acad Sci U S A 2006, 103:17432-17437.

85. Jones EA, English A, Henshaw K, Kinsey SE, Markham AF, Emery $\mathrm{P}$, McGonagle D: Enumeration and phenotypic characterization of synovial fluid multipotential mesenchymal progenitor cells in inflammatory and degenerative arthritis. Arthritis Rheum 2004, 50:817-827.

86. Bocelli-Tyndall C, Bracci L, Spagnoli G, Braccini A, Bouchenaki M, Ceredig R, Pistoia V, Martin I, Tyndall A: Bone marrow mesenchymal stromal cells (BM-MSCs) from healthy donors and auto-immune disease patients reduce the proliferation of autologous- and allogeneic-stimulated lymphocytes in vitro. Rheumatology (Oxford) 2007, 46:403-408.

87. Zheng ZH, Li XY, Ding J, Jia JF, Zhu P: Allogeneic mesenchymal stem cell and mesenchymal stem cell-differentiated chondrocyte suppress the responses of type II collagen-reactive T cells in rheumatoid arthritis. Rheumatology (Oxford) 2008, 47: 22-30.

88. Djouad F, Fritz V, Apparailly F, Louis-Plence P, Bony C, Sany J, Jorgensen C, Noel D: Reversal of the immunosuppressive properties of mesenchymal stem cells by tumor necrosis factor alpha in collagen-induced arthritis. Arthritis Rheum 2005, 52:1595-1603.

89. Tuan RS, Boland G, Tuli R: Adult mesenchymal stem cells and cell based tissue engineering. Arthritis Res Ther 2003, 5:32-45. 